\title{
PERANCANGAN ULANG SISTEM HVAC PADA GEDUNG PERKANTORAN X DI JAKARTA DENGAN METODE CLTD
}

\author{
Mohamad Faizal $\mathbf{H}^{1)}$ dan Rudi Saputra ${ }^{2)}$ \\ Staf Pengajar Program Studi Teknik Mesin, Institut Sains dan Teknologi Nasional \\ Jl. Moh. Kahfi II, Jagakarsa, Jakarta 12640, Indonesia \\ E-mail: mfaizalh44@yahoo.com
}

\begin{abstract}
HVAC system ( Heating Ventilating and Air Conditioning ) is a system that serves to organize temperatures and humidity the air on a room, that feels comfortable condition. In redesigned system HVAC to 8 floors office buildings, by using CLTD method (cooling load temperature difference), where the state of temperature design at $73,4^{\circ} \mathrm{F}$ and $50 \%$ moisture. Existing cooling load 8.880 .000 $\mathrm{BTU} / \mathrm{hr}$ and air supply existing of 264.180 CFM. Redesigned calculation of cooling load is 11.626 .701 $\mathrm{BTU} / \mathrm{hr}$, where there is increased by $30.9 \%$, and obtained needs air supply of 343.456,73 CFM and increased by $30 \%$. Chiller system installation at the building using air cooled chiller, existing chiller using four chiller units of 250 tons refigerant each and one units for back up. Based of calculation obtained chiller capacity is 969 tons refrigerant, so that four units chiller available must in operates with 17 Air Handling Unit (AHU) to be optimum cooling,with dimension ducting 35 in the largest and smallest 9,5 in.
\end{abstract}

Keywords : HVAC, CLTD, Cooling Load, Air Supply, Chiller Unit, AHU

\section{PENDAHULUAN}

HVAC (Heating Ventilating and Air Conditioning) adalah suatu sistem yang berfungsi untuk mengatur temperatur dan kelembaban udara pada suatu ruangan, agar kondisi temperatur dan kelembaban udara pada suatu ruangan tersebut menjadi nyaman. Keberadaan sistem HVAC telah menjadi keharusan bagi bangunan-bangunan besar, khususnya di negara yang beriklim tropis seperti di Indonesia. Jakarta merupakan ibu kota Indonesia sekaligus sebagai pusat ekonomi Indonesia, segala bentuk aktivitas bisnis banyak berpusat di Jakarta, baik berupa perkantoran, perbankan, perhotelan, pariwisata, pusat perbelanjaan dll, yang ditunjang oleh gedung bertingkat. Kondisi tersebut mengharuskan adanya sistem HVAC yang dapat memberikan kenyamanan udara di dalam gedung bagi pelaku yang beraktivitas.

Dilakukannya renovasi pada instalasi penerangan di gedung perkantoran $\mathrm{X}$, membuat bertambahnya jumlah penghuni gedung, peralatan elektronik, yang dengan sendirinya akan menaikkan beban panas, sehingga keadaan tersebut mengakibatkan kenaikan beban pada sistem HVAC yang telah ada.

Dengan latar belakang diatas perlu dilakukannya perancangan ulang pada sistem HVAC yang terpasang dengan dasar data baru penambahan beban.

Dasar perancangan meggunakan metode
CLTD (Cooling Load Temperature difference), perancangan ulang ini dilakukan saat beban baru berfungsi yaitu pada bulan September 2015, waktu desain jam 13.00 WIB, agar pemilihan mesin HVAC dapat memenuhi beban perancangan sesuai standar kenyamanan (comfortable condition) yaitu $73,4^{\circ} \mathrm{F}$ dan $50 \%$ RH.

Perancangan ulang beban pendingin dilakukan pada gedung perkantoran berlantai 8 dengan lokasi di Kebayoran Baru-Jaksel, mengggunakan metoda CLTD.

\section{METODOLOGI \\ Diagram Alir Penelitian}

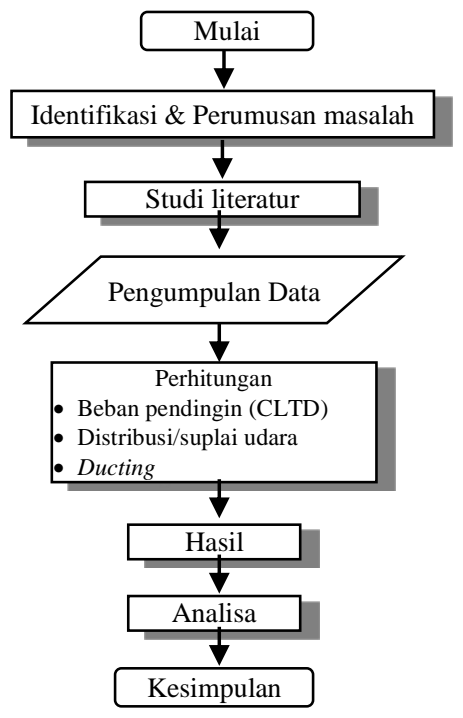

Gambar 1. Diagram Alir Penelitian 
DATA SPESIFIKASI

Lokasi dan Fungsi Gedung

Geografis $: 6^{\circ} \mathrm{LS}-7^{\circ} \mathrm{LS}$

Letak Bangunan : Kebayoran Baru

Fungsi Bangunan : Perkantoran.

Arah Bangunan : menghadap ke Selatan.

\section{Data Fisik Gedung}

1. Kondisi Temperatur dan Kelembaban wilayah Jakarta

Temperatur rata-rata maksimum di Jakarta terjadi pada bulan September.

Temperatur rata-rata : $95^{\circ} \mathrm{F}$ dan

Kelembaban : $50 \%$

2. Temperatur dan Kelembaban Desain

Temperatur : $73,4^{\circ} \mathrm{F}$ dan

Kelembaban : $50 \%$

3. Dimensi Bangunan

Luas : : 165.964,13 $\mathrm{ft}^{2}$

Tinggi : lantai $1(17,06 \mathrm{ft})$, lantai 2 s/d 8 masing-masing memiiki ketinggian $14,10 \mathrm{ft}$.

Dinding eksterior bangunan keseluruhan terdiri dari kaca, dimensi kaca perlantai/ peruangan, serta dimensi dinding partisi, dan lantai dapat dilihat pada tabel berikut:

Tabel 1. Luas dinding (kaca), dinding partisi lantai 1

\begin{tabular}{|c|c|c|c|c|c|c|}
\hline Lantai 1 & \multicolumn{4}{|c|}{ Mata Angin } & \multicolumn{2}{c|}{$\begin{array}{c}\text { Dimensi Lantai \& } \\
\text { Dinding Partisi }\end{array}$} \\
\hline Ruang & $\begin{array}{c}\text { Timur } \\
\left(\mathrm{ft}^{2}\right)\end{array}$ & $\begin{array}{c}\text { Barat } \\
\left(\mathrm{ft}^{2}\right)\end{array}$ & $\begin{array}{c}\text { Utara } \\
\left(\mathrm{ft}^{2}\right)\end{array}$ & $\begin{array}{c}\text { Selatan } \\
\left(\mathrm{ft}^{2}\right)\end{array}$ & $\begin{array}{c}\text { Lantai } \\
\left(\mathrm{ft}^{2}\right)\end{array}$ & $\begin{array}{c}\text { Partisi } \\
\left(\mathrm{ft}^{2}\right)\end{array}$ \\
\hline Food Court & $\begin{array}{c}1208,9 \\
6\end{array}$ & 805,91 & 805,91 & - & 4463,23 & 805,9 \\
\hline Tenant & - & 895,52 & - & 1208,96 & 3719,58 & $\begin{array}{c}699,6 \\
3\end{array}$ \\
\hline Lobby & - & 223,82 & 1359,85 & 1359,85 & 2371,5 & $\begin{array}{c}7938 \\
6\end{array}$ \\
\hline Exhibition/Gallery & 805,91 & - & - & 1611,82 & 4463,23 & $\begin{array}{c}669,6 \\
3\end{array}$ \\
\hline Mitra 1 & - & - & 402,95 & - & 485,62 & - \\
\hline Mitra 2 & - & - & 402,95 & - & 485,62 & - \\
\hline Mitra 3 & - & - & 402,95 & - & 485,62 & - \\
\hline Ruang UPS & - & - & 212,62 & - & 294,3 & 402,9 \\
\hline Koridor & - & - & 190,29 & - & 681,81 & - \\
\hline
\end{tabular}

Tabel 2. Luas dinding (kaca), dinding partisi lantai 2

\begin{tabular}{|c|c|c|c|c|c|c|}
\hline \multirow[t]{2}{*}{ Ruangan } & \multicolumn{4}{|c|}{$\begin{array}{c}\text { Mata Angin } \\
\text { Dimensi dinding ekstrior (kaca) }\end{array}$} & \multicolumn{2}{|c|}{$\begin{array}{c}\text { Dimensi Lantai \& } \\
\text { Dinding Partisi }\end{array}$} \\
\hline & $\begin{array}{c}\text { Timur } \\
\left(\mathrm{ft}^{2}\right)\end{array}$ & $\begin{array}{c}\text { Barat } \\
\left(\mathrm{ft}^{2}\right)\end{array}$ & $\begin{array}{c}\text { Utara } \\
\left(\mathrm{ft}^{2}\right)\end{array}$ & $\begin{array}{c}\text { Selatan } \\
\left(\mathrm{ft}^{2}\right)\end{array}$ & $\begin{array}{l}\text { Lantai } \\
\left(\mathrm{ft}^{2}\right)\end{array}$ & $\begin{array}{c}\text { Partisi } \\
\left(\mathrm{ft}^{2}\right)\end{array}$ \\
\hline Lobby & - & - & $\begin{array}{c}374,8 \\
2\end{array}$ & 1124,61 & 3538,60 & 2371,5 \\
\hline Bagian Umum & $\begin{array}{c}837,7 \\
0\end{array}$ & 846,96 & $\begin{array}{c}444,2 \\
9\end{array}$ & - & 4648,46 & - \\
\hline Kabag. umum & $\begin{array}{c}161,9 \\
8\end{array}$ & - & $\begin{array}{c}222,1 \\
4\end{array}$ & - & 180,81 & - \\
\hline R.Arsip & - & 152,730 & - & - & 191,73 & 249,83 \\
\hline Rapat 1 & - & 333,22 & - & - & 1115,92 & - \\
\hline Kerja Sek.Dierek & & 666,45 & - & 142,57 & 1646,31 & 138,81 \\
\hline $\begin{array}{c}\text { Istrahat Sek } \\
\text { Direk } \\
\end{array}$ & - & - & - & 194,25 & 121,86 & 56,7 \\
\hline $\begin{array}{c}\text { TU, Resepsionis } \\
1, \text { Lounge } 1 \\
\end{array}$ & - & - & - & 476,67 & 1596,35 & 669,69 \\
\hline Musholla & - & - & $\begin{array}{c}333,2 \\
2 \\
\end{array}$ & - & 255,57 & - \\
\hline $\begin{array}{c}\text { TU ,Resepsionis } \\
2 \text { \& Lounge } 2 \\
\end{array}$ & & & $\begin{array}{c}333,2 \\
2 \\
\end{array}$ & 333,22 & 1673,78 & - \\
\hline Lounge 3 & - & - & - & 333,22 & 1115,9 & - \\
\hline Kerja Direktur & $\begin{array}{c}666,4 \\
5\end{array}$ & - & - & 666,45 & 2231,90 & - \\
\hline Istirahat Direktur & - & & $\begin{array}{c}194,2 \\
5\end{array}$ & - & 212 & 212,89 \\
\hline Rapat 2 & - & - & $\begin{array}{c}666,4 \\
5\end{array}$ & - & 1115,92 & - \\
\hline
\end{tabular}

Tabel 3. Luas dinding (kaca), dinding partisi lantai 3

\begin{tabular}{|c|c|c|c|c|c|c|}
\hline \multirow[t]{2}{*}{ Ruangan } & \multicolumn{4}{|c|}{$\begin{array}{c}\text { Mata Angin } \\
\text { Dimensi dinding ekstrior (kaca) }\end{array}$} & \multicolumn{2}{|c|}{$\begin{array}{c}\text { Dimensi Lantai \& } \\
\text { Dinding Partisi }\end{array}$} \\
\hline & $\begin{array}{c}\text { Timur } \\
\left(\mathrm{ft}^{2}\right)\end{array}$ & $\begin{array}{c}\text { Barat } \\
\left(\mathrm{ft}^{2}\right)\end{array}$ & $\begin{array}{c}\text { Utara } \\
\left(\mathrm{ft}^{2}\right)\end{array}$ & $\begin{array}{c}\text { Selatan } \\
\left(\mathrm{ft}^{2}\right)\end{array}$ & $\begin{array}{l}\text { Lantai } \\
\left(\mathrm{ft}^{2}\right)\end{array}$ & $\begin{array}{c}\text { Dinding } \\
\left(\mathrm{ft}^{2}\right)\end{array}$ \\
\hline Arsip & - & $\begin{array}{c}152,7 \\
3\end{array}$ & - & - & 191,73 & 249,83 \\
\hline Kabsudit. Kebijakan & $\begin{array}{c}166,6 \\
03 \\
\end{array}$ & - & - & - & 185,88 & - \\
\hline Kabsudit Program & $\begin{array}{c}166,6 \\
03\end{array}$ & - & - & - & 185,88 & - \\
\hline Pantai \& Rawa 1 & $\begin{array}{c}666,4 \\
5\end{array}$ & $\begin{array}{c}1331, \\
7\end{array}$ & $\begin{array}{c}666,4 \\
5\end{array}$ & 666,45 & 5497,45 & - \\
\hline Santai 1 & - & $\begin{array}{c}333,2 \\
3\end{array}$ & - & - & 557 & 333,23 \\
\hline Kerja Direktur & - & $\begin{array}{c}333,2 \\
3 \\
\end{array}$ & $\begin{array}{c}819,1 \\
9\end{array}$ & 333,23 & 1611,8 & 123 \\
\hline Istrahat Direktur & - & - & - & 199 & 157 & 107,43 \\
\hline Tunggu, Resepsion & $\begin{array}{c}333,2 \\
3\end{array}$ & - & - & - & 1229,08 & 518,35 \\
\hline Staff TU & - & - & - & 485,96 & 338,89 & - \\
\hline Musholla & - & - & $\begin{array}{c}333,2 \\
2\end{array}$ & - & 255,57 & - \\
\hline Lobby & & & $\begin{array}{c}374,8 \\
8\end{array}$ & 138,84 & 1271,05 & 1434,48 \\
\hline Kabsudit Pengamanan & - & - & & 166,6 & 185,88 & - \\
\hline Kabsudit Perencana & - & - & 166,6 & - & 185,88 & - \\
\hline Kabsudit. Pendayagunaan & - & - & - & 166,6 & 185,88 & - \\
\hline Pantai \& Rawa 2 & - & & $\begin{array}{c}1374, \\
58\end{array}$ & 999,62 & 3904,73 & 838,23 \\
\hline Pantai \& Rawa 3 & $\begin{array}{c}476,6 \\
7\end{array}$ & - & $\begin{array}{c}999,6 \\
2\end{array}$ & $\begin{array}{c}1374,5 \\
8\end{array}$ & 3718,85 & 565,1 \\
\hline Santai 2 & $\begin{array}{c}333,2 \\
3\end{array}$ & - & - & - & 557 & 333,23 \\
\hline
\end{tabular}

Tabel 4. Luas dinding (kaca), dinding partisi lantai 4

\begin{tabular}{|c|c|c|c|c|c|c|}
\hline \multirow[t]{2}{*}{ Ruangan } & \multicolumn{4}{|c|}{$\begin{array}{c}\text { Mata Angin } \\
\text { Dimensi dinding ekstrior (kaca) }\end{array}$} & \multicolumn{2}{|c|}{$\begin{array}{c}\text { Dimensi Lantai \& } \\
\text { Dinding Partisi } \\
\end{array}$} \\
\hline & $\begin{array}{c}\text { Timur } \\
\left(\mathrm{ft}^{2}\right)\end{array}$ & $\begin{array}{c}\text { Barat } \\
\left(\mathrm{ft}^{2}\right)\end{array}$ & $\begin{array}{c}\text { Utara } \\
\left(\mathrm{ft}^{2}\right)\end{array}$ & $\begin{array}{c}\text { Selatan } \\
\left(\mathrm{ft}^{2}\right)\end{array}$ & $\begin{array}{c}\text { Lantai } \\
\left(\mathrm{ft}^{2}\right)\end{array}$ & $\begin{array}{c}\text { Dinding } \\
\left(\mathrm{ft}^{2}\right)\end{array}$ \\
\hline Arsip & - & $\begin{array}{c}152,7 \\
3\end{array}$ & - & - & 191,73 & 249,83 \\
\hline $\begin{array}{c}\text { Kabsudit. } \\
\text { Kebijakan } \\
\end{array}$ & 166,603 & - & - & - & 185,88 & - \\
\hline Kabsudit Program & 166,603 & - & - & - & 185,88 & - \\
\hline Pantai \& Rawa 1 & 666,45 & $\begin{array}{c}1331, \\
7 \\
\end{array}$ & 666,45 & 666,45 & 5497,45 & - \\
\hline Santai 1 & - & $\begin{array}{c}333,2 \\
3 \\
\end{array}$ & - & - & 557 & 333,23 \\
\hline Kerja Direktur & - & $\begin{array}{c}333,2 \\
3\end{array}$ & 819,19 & 333,23 & 1611,8 & 123 \\
\hline Istrahat Direktur & - & - & - & 199 & 157 & 107,43 \\
\hline Tunggu, Resepsion & 333,23 & - & - & - & 1229,08 & 518,35 \\
\hline Staff TU & - & - & - & 485,96 & 338,89 & - \\
\hline Musholla & - & - & 333,22 & - & 255,57 & - \\
\hline Lobby & & & 374,88 & 138,84 & 1271,05 & 1434,48 \\
\hline $\begin{array}{c}\text { Kabsudit } \\
\text { Pengamanan } \\
\end{array}$ & - & - & & 166,6 & 185,88 & - \\
\hline Kabsudit Perencana & - & - & 166,6 & - & 185,88 & - \\
\hline $\begin{array}{c}\text { Kabsudit. } \\
\text { Pendayagunaan } \\
\end{array}$ & - & - & - & 166,6 & 185,88 & - \\
\hline Pantai \& Rawa 2 & - & & 1374,58 & 999,62 & 3904,73 & 838,23 \\
\hline Pantai \& Rawa 3 & 476,67 & - & $\begin{array}{l}999,62 \\
\end{array}$ & 1374,58 & 3718,85 & 565,1 \\
\hline Santai 2 & 333,23 & - & - & - & 557 & 333,23 \\
\hline
\end{tabular}

Tabel 5. Luas dinding (kaca), dinding partisi lantai 5

\begin{tabular}{|c|c|c|c|c|c|c|}
\hline \multirow[t]{2}{*}{ Ruangan } & \multicolumn{4}{|c|}{$\begin{array}{c}\text { Mata Angin } \\
\text { Dimensi dinding ekstrior (kaca) }\end{array}$} & \multicolumn{2}{|c|}{$\begin{array}{c}\text { Dimensi Lantai \& } \\
\text { Dinding Partisi }\end{array}$} \\
\hline & $\begin{array}{c}\text { Timur } \\
\left(\mathrm{ft}^{2}\right)\end{array}$ & $\begin{array}{c}\text { Barat } \\
\left(\mathrm{ft}^{2}\right)\end{array}$ & $\begin{array}{c}\text { Utara } \\
\left(\mathrm{ft}^{2}\right)\end{array}$ & $\begin{array}{c}\text { Selatan } \\
\left(\mathrm{ft}^{2}\right)\end{array}$ & $\begin{array}{c}\text { Lantai } \\
\left(\mathrm{ft}^{2}\right)\end{array}$ & $\begin{array}{c}\text { Dinding } \\
\left(\mathrm{ft}^{2}\right)\end{array}$ \\
\hline Arsip & - & $\begin{array}{c}152,7 \\
3\end{array}$ & - & - & 191,73 & 249,83 \\
\hline $\begin{array}{l}\text { Kabsudit. } \\
\text { Kebijakan }\end{array}$ & 166,603 & - & - & - & 185,88 & - \\
\hline Kabsudit Program & 166,603 & - & - & - & 185,88 & - \\
\hline Pantai \& Rawa 1 & 666,45 & $\begin{array}{c}1331, \\
7\end{array}$ & 666,45 & 666,45 & 5497,45 & - \\
\hline Santai 1 & - & $\begin{array}{c}333,2 \\
3\end{array}$ & - & - & 557 & 333,23 \\
\hline Kerja Direktur & - & $\begin{array}{c}333,2 \\
3\end{array}$ & 819,19 & 333,23 & 1611,8 & 123 \\
\hline Istrahat Direktur & - & - & - & 199 & 157 & 107,43 \\
\hline Tunggu, Resepsion & 333,23 & - & - & - & 1229,08 & 518,35 \\
\hline Staff TU & - & - & - & 485,96 & 338,89 & - \\
\hline Musholla & - & - & 333,22 & - & 255,57 & - \\
\hline Lobby & & & 374,88 & 138,84 & 1271,05 & 1434,48 \\
\hline $\begin{array}{c}\text { Kabsudit } \\
\text { Pengamanan } \\
\end{array}$ & - & - & & 166,6 & 185,88 & - \\
\hline Kabsudit Perencana & - & - & 166,6 & - & 185,88 & - \\
\hline $\begin{array}{c}\text { Kabsudit. } \\
\text { Pendayagunaan } \\
\end{array}$ & - & - & - & 166,6 & 185,88 & - \\
\hline Pantai \& Rawa 2 & - & & 1374,58 & 999,62 & 3904,73 & 838,23 \\
\hline Pantai \& Rawa 3 & 476,67 & - & 999,62 & 1374,58 & 3718,85 & 565,1 \\
\hline Santai 2 & 333,23 & - & - & - & 557 & 333,23 \\
\hline
\end{tabular}


Tabel 6. Luas dinding (kaca), dinding partisi lantai 6

\begin{tabular}{|c|c|c|c|c|c|c|}
\hline \multirow{2}{*}{ Ruangan } & \multicolumn{5}{|c|}{ Mata Angin } & \multicolumn{2}{c|}{$\begin{array}{c}\text { Dimensi Lantai \& } \\
\text { Dinding Partisi }\end{array}$} \\
\cline { 2 - 7 } & $\begin{array}{c}\text { Timur } \\
\left(\mathrm{ft}^{2}\right)\end{array}$ & $\begin{array}{c}\text { Barat } \\
\left(\mathrm{ft}^{2}\right)\end{array}$ & $\begin{array}{c}\text { Utara } \\
\left(\mathrm{ft}^{2}\right)\end{array}$ & $\begin{array}{c}\text { Selatan } \\
\left(\mathrm{ft}^{2}\right)\end{array}$ & $\begin{array}{c}\text { Lantai } \\
\left(\mathrm{ft}^{2}\right)\end{array}$ & $\begin{array}{c}\text { Dinding } \\
\left(\mathrm{ft}^{2}\right)\end{array}$ \\
\hline Arsip & - & $\begin{array}{c}152,7 \\
3\end{array}$ & - & - & 191,73 & 249,83 \\
\hline Kabsudit. Kebijakan & $\begin{array}{c}166,60 \\
3\end{array}$ & - & - & - & 185,88 & - \\
\hline Kabsudit Program & $\begin{array}{c}166,60 \\
3\end{array}$ & - & - & - & 185,88 & - \\
\hline Pantai \& Rawa 1 & 666,45 & $\begin{array}{c}1331, \\
7\end{array}$ & 666,45 & 666,45 & 5497,45 & - \\
\hline Santai 1 & - & 333,2 & - & - & 557 & 333,23 \\
\hline Kerja Direktur & - & 333,2 & 819,19 & 333,23 & 1611,8 & 123 \\
\hline Istrahat Direktur & - & - & - & 199 & 157 & 107,43 \\
\hline Tunggu, Resepsion & 333,23 & - & - & - & 1229,08 & 518,35 \\
\hline Staff TU & - & - & - & 485,96 & 338,89 & - \\
\hline Musholla & - & - & 333,22 & - & 255,57 & - \\
\hline Lobby & & & 374,88 & 138,84 & 1271,05 & 1434,48 \\
\hline Kabsudit Pengamanan & - & - & & 166,6 & 185,88 & - \\
\hline Kabsudit Perencana & - & - & 166,6 & - & 185,88 & - \\
\hline $\begin{array}{c}\text { Kabsudit. } \\
\text { Pendayagunaan }\end{array}$ & - & - & - & 166,6 & 185,88 & - \\
\hline Pantai \& Rawa 2 & - & & 1374,58 & 999,62 & 3904,73 & 838,23 \\
\hline Pantai \& Rawa 3 & 476,67 & - & 999,62 & 1374,58 & 3718,85 & 565,1 \\
\hline Santai 2 & 333,23 & - & - & - & 557 & 333,23 \\
\hline & & & & & & \\
\hline
\end{tabular}

Tabel 7. Luas dinding (kaca), dinding partisi lantai 7

\begin{tabular}{|c|c|c|c|c|c|c|}
\hline \multirow[t]{2}{*}{ Ruangan } & \multicolumn{4}{|c|}{$\begin{array}{c}\text { Mata Angin } \\
\text { Dimensi dinding ekstrior (kaca) }\end{array}$} & \multicolumn{2}{|c|}{$\begin{array}{l}\text { Dimensi Lantai \& } \\
\text { Dinding Partisi }\end{array}$} \\
\hline & $\begin{array}{c}\text { Timur } \\
\left(\mathrm{ft}^{2}\right)\end{array}$ & $\begin{array}{c}\text { Barat } \\
\left(\mathrm{ft}^{2}\right)\end{array}$ & $\begin{array}{c}\text { Utara } \\
\left(\mathrm{ft}^{2}\right)\end{array}$ & $\begin{array}{c}\text { Selatan } \\
\left(\mathrm{ft}^{2}\right)\end{array}$ & $\begin{array}{c}\text { Lantai } \\
\left(\mathrm{ft}^{2}\right)\end{array}$ & $\begin{array}{c}\text { Dinding } \\
\left(\mathrm{ft}^{2}\right)\end{array}$ \\
\hline Arsip & - & $\begin{array}{c}152,7 \\
3\end{array}$ & - & - & 191,73 & 249,83 \\
\hline $\begin{array}{l}\text { Kabsudit. } \\
\text { Kebijakan }\end{array}$ & 166,603 & - & - & - & 185,88 & - \\
\hline Kabsudit Program & 166,603 & - & - & - & 185,88 & - \\
\hline Pantai \& Rawa 1 & 666,45 & $\begin{array}{c}1331, \\
7\end{array}$ & 666,45 & 666,45 & 5497,45 & - \\
\hline Santai 1 & - & $\begin{array}{c}333,2 \\
3\end{array}$ & - & - & 557 & 333,23 \\
\hline Kerja Direktur & - & $\begin{array}{c}333,2 \\
3\end{array}$ & 819,19 & 333,23 & 1611,8 & 123 \\
\hline Istrahat Direktur & - & - & - & 199 & 157 & 107,43 \\
\hline Tunggu, Resepsion & 333,23 & - & - & - & 1229,08 & 518,35 \\
\hline Staff TU & - & - & - & 485,96 & 338,89 & - \\
\hline Musholla & - & - & 333,22 & - & 255,57 & - \\
\hline Lobby & & & 374,88 & 138,84 & 1271,05 & 1434,48 \\
\hline $\begin{array}{c}\text { Kabsudit } \\
\text { Pengamanan }\end{array}$ & - & - & & 166,6 & 185,88 & - \\
\hline Kabsudit Perencana & - & - & 166,6 & - & 185,88 & - \\
\hline $\begin{array}{c}\text { Kabsudit. } \\
\text { Pendayagunaan }\end{array}$ & - & - & - & 166,6 & 185,88 & - \\
\hline Pantai \& Rawa 2 & - & & 1374,58 & 999,62 & 3904,73 & 838,23 \\
\hline Pantai \& Rawa 3 & 476,67 & - & 999,62 & 1374,58 & 3718,85 & 565,1 \\
\hline Santai 2 & 333,23 & - & - & - & 557 & 333,23 \\
\hline
\end{tabular}

Tabel 8. Luas dinding (kaca), dinding partisi lantai 8

\begin{tabular}{|c|c|c|c|c|c|c|}
\hline \multirow{2}{*}{ Ruangan } & \multicolumn{5}{|c|}{ Mata Angin } & \multicolumn{2}{c|}{$\begin{array}{c}\text { Dimensi Lantai \& Dinding } \\
\text { Partisi }\end{array}$} \\
\cline { 2 - 7 } & $\begin{array}{c}\text { Timur } \\
\left(\mathrm{ft}^{2}\right)\end{array}$ & $\begin{array}{c}\text { Barat } \\
\left(\mathrm{ft}^{2}\right)\end{array}$ & $\begin{array}{c}\text { Utara } \\
\left(\mathrm{ft}^{2}\right)\end{array}$ & $\begin{array}{c}\text { Selatan } \\
\left(\mathrm{ft}^{2}\right)\end{array}$ & $\begin{array}{c}\text { Lantai } \\
\left(\mathrm{ft}^{2}\right)\end{array}$ & $\begin{array}{c}\text { Dinding } \\
\left(\mathrm{ft}^{2}\right)\end{array}$ \\
\hline Arsip & - & 152,73 & - & - & 191,73 & 249,83 \\
\hline $\begin{array}{c}\text { Kabsudit. } \\
\text { Kebijakan }\end{array}$ & 166,603 & - & - & - & 185,88 & - \\
\hline Kabsudit Program & 166,603 & - & - & - & 185,88 & - \\
\hline Pantai \& Rawa 1 & 666,45 & 1331,7 & 666,45 & 666,45 & 5497,45 & - \\
\hline Santai 1 & - & 333,23 & - & - & 557 & 333,23 \\
\hline Kerja Direktur & - & 333,23 & 819,19 & 333,23 & 1611,8 & 123 \\
\hline Istrahat Direktur & - & - & - & 199 & 157 & 107,43 \\
\hline $\begin{array}{c}\text { Tunggu, } \\
\text { Resepsion }\end{array}$ & 333,23 & - & - & - & 1229,08 & 518,35 \\
\hline Staff TU & - & - & - & 485,96 & 338,89 & - \\
\hline Musholla & - & - & 333,22 & - & 255,57 & - \\
\hline Lobby & & & 374,88 & 138,84 & 1271,05 & 1434,48 \\
\hline $\begin{array}{c}\text { Kabsudit } \\
\text { Pengamanan }\end{array}$ & - & - & & 166,6 & 185,88 & - \\
\hline $\begin{array}{c}\text { Kabsudit } \\
\text { Perencana }\end{array}$ & - & - & 166,6 & - & 185,88 & - \\
\hline $\begin{array}{c}\text { Kabsudit. } \\
\text { Pendayagunaan }\end{array}$ & - & - & - & 166,6 & 185,88 & - \\
\hline Pantai \& Rawa 2 & - & & 1374,58 & 999,62 & 3904,73 & 838,23 \\
\hline Pantai \& Rawa 3 & 476,67 & - & 999,62 & 1374,58 & 3718,85 & 565,1 \\
\hline Santai 2 & 333,23 & - & - & - & 557 & 333,23 \\
\hline & & & & & & \\
\hline
\end{tabular}

\section{Beban Ruangan}

Beban pendinginan peruangan meliputi beban penghuni peruangan, beban peralatan elektronik, dan beban penerangan.

Tabel 9. Beban ruangan lantai 1

\begin{tabular}{|c|c|c|c|c|c|c|c|c|c|}
\hline \multirow{2}{*}{ Ruangan } & \multicolumn{9}{|c|}{ Jenis beban ruangan } \\
\cline { 2 - 11 } & Orang & $\begin{array}{c}\text { Lamp } \\
\text { u }\end{array}$ & Komp & $\begin{array}{c}\text { Pri } \\
\text { nter }\end{array}$ & $\begin{array}{c}\text { T } \\
\mathrm{V}\end{array}$ & $\begin{array}{c}\text { F } \\
\text { a }\end{array}$ & $\begin{array}{c}\text { Pro } \\
\text { yek } \\
\text { tor }\end{array}$ & $\begin{array}{c}\text { Dispe } \\
\text { nser }\end{array}$ & $\begin{array}{c}\text { Kul } \\
\text { kas }\end{array}$ \\
\hline $\begin{array}{c}\text { Food } \\
\text { Court/kantin }\end{array}$ & 40 & 45 & - & - & 2 & - & - & 2 & 2 \\
\hline Tenant & 30 & 48 & 30 & - & - & - & - & - & - \\
\hline Lobby & 10 & 72 & - & - & 2 & - & - & - & - \\
\hline Exhibition/Galler & 50 & 105 & - & - & - & - & - & - & - \\
\hline y & & & & & & & & & \\
\hline Mitra 1 & 5 & 6 & - & - & - & - & - & - & - \\
\hline Mitra 2 & 5 & 6 & - & - & - & - & - & - & - \\
\hline Mitra 3 & 5 & 6 & - & - & - & - & - & - & - \\
\hline Ruang UPS & 1 & 2 & - & - & - & - & - & - & - \\
\hline Koridor & 2 & 10 & - & - & - & - & - & - & - \\
\hline
\end{tabular}

Keterangan :

- Penerangan ruang Food Court, tenant, lobby, ruang mitra, ruang UPS menggunakan jenis lampu Reccesed Mounted Flourescent 72 Watt

- Penerangan Lobby menggunakan jenis lampu Reccesed Mounted Downlight 18 Watt sebanyak 40 unit dan 32 unit Surface Mounted Flourescent 21 Watt

- Penerangan Ruang Gallery dan koridor menggunakan jenis lampu Reccesed Mounted Downlight 18 Watt

Tabel 10. Beban ruangan lantai 2

\begin{tabular}{|c|c|c|c|c|c|c|c|c|c|}
\hline \multirow[b]{2}{*}{ Ruangan } & \multicolumn{9}{|c|}{ Jenis beban ruangan } \\
\hline & $\begin{array}{c}\text { Or } \\
\text { an } \\
\mathrm{g}\end{array}$ & $\begin{array}{c}\mathrm{La} \\
\mathrm{mpu}\end{array}$ & $\begin{array}{l}\text { Ko } \\
\text { mp }\end{array}$ & $\begin{array}{c}\text { Prin } \\
\text { ter }\end{array}$ & $\mathrm{TV}$ & Fax & $\begin{array}{c}\text { Proye } \\
\text { ktor }\end{array}$ & $\begin{array}{c}\text { Di } \\
\text { spe } \\
\text { nse } \\
\text { r }\end{array}$ & $\begin{array}{l}\text { Kul } \\
\text { kas }\end{array}$ \\
\hline Lobby & 5 & 60 & - & - & - & - & - & - & - \\
\hline Bagian Umum & 60 & 80 & 60 & 5 & - & 5 & - & - & - \\
\hline Kabag. umum & 1 & 4 & 1 & 1 & - & 1 & - & - & - \\
\hline R.Arsip & 1 & 4 & - & - & - & - & - & - & - \\
\hline Rapat 1 & 15 & 32 & - & - & - & - & 2 & - & - \\
\hline Kerja Set.Dierek & 1 & 16 & 1 & 1 & 1 & 1 & - & 1 & - \\
\hline Istrahat Set Direk & 1 & 1 & - & - & - & - & - & - & - \\
\hline $\begin{array}{c}\text { TU 1, } \\
\text { Resepsionis 1, } \\
\text { Lounge } 1\end{array}$ & 8 & 18 & 5 & 1 & - & 1 & - & - & - \\
\hline Musholla & 3 & 5 & - & - & - & - & - & - & - \\
\hline $\begin{array}{c}\text { TU 2, } \\
\text { Resepsionis } 2 \& \\
\text { Lounge } 2\end{array}$ & 8 & 16 & 5 & 1 & - & 1 & - & - & - \\
\hline Lounge 3 & 5 & 12 & - & - & - & - & - & - & 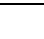 \\
\hline Kerja Direktur & 1 & 24 & 1 & 1 & 1 & 1 & - & 1 & - \\
\hline Istirahat Direktur & 1 & 3 & - & - & - & - & - & - & - \\
\hline Rapat 2 & 15 & 32 & - & - & - & - & 2 & - & - \\
\hline
\end{tabular}


Tabel 11. Beban ruangan lantai 3

\begin{tabular}{|c|c|c|c|c|c|c|c|c|c|}
\hline \multirow[b]{2}{*}{ Ruangan } & \multicolumn{9}{|c|}{ Jenis beban ruangan } \\
\hline & Orang & Lampu & Komp & Printer & TV & Fax & Proyektor & Dispenser & Kulkas \\
\hline Arsip & 1 & 4 & - & - & - & - & - & - & - \\
\hline $\begin{array}{c}\text { Kabag } \\
\text { keegawaian }\end{array}$ & 1 & 4 & 1 & 1 & - & 1 & - & - & - \\
\hline $\begin{array}{l}\text { Kabsudit.eval } \\
\text { uasi } 1\end{array}$ & 1 & 4 & 1 & 1 & - & 1 & - & - & - \\
\hline $\begin{array}{c}\text { Bagian } \\
\text { kepegawaian }\end{array}$ & 80 & 100 & 80 & 5 & - & 5 & - & - & - \\
\hline Santai 1 & 4 & 9 & - & - & - & - & - & - & - \\
\hline Kerja Direktur & 1 & 18 & 1 & 1 & 1 & 1 & - & 1 & - \\
\hline $\begin{array}{l}\text { Istrahat } \\
\text { Direktur }\end{array}$ & 1 & 1 & - & - & - & - & - & - & - \\
\hline $\begin{array}{l}\text { Tunggu, } \\
\text { Resepsion }\end{array}$ & 8 & 16 & - & - & - & - & - & - & - \\
\hline Staff TU & 3 & 6 & 3 & 1 & - & 1 & - & - & - \\
\hline Musholla & 3 & 5 & - & - & - & - & - & - & - \\
\hline Lobby & 5 & 46 & - & - & - & - & - & - & - \\
\hline Kabag hukum & 1 & 4 & 1 & 1 & - & - & - & - & - \\
\hline $\begin{array}{l}\text { Kabsudit. } \\
\text { evaluasi } 2\end{array}$ & 1 & 4 & 1 & 1 & - & - & - & - & - \\
\hline $\begin{array}{c}\text { Kabag } \\
\text { keuangan }\end{array}$ & 1 & 4 & 1 & 1 & - & - & - & - & - \\
\hline Bagian hukum & 45 & 56 & 45 & 5 & - & 2 & - & - & - \\
\hline $\begin{array}{c}\text { Bagian } \\
\text { keuangan }\end{array}$ & 45 & 56 & 45 & 5 & - & 2 & - & - & - \\
\hline Santai 2 & 4 & 9 & - & - & - & - & - & - & - \\
\hline
\end{tabular}

Keterangan :

Penerangan untuk lantai $3 \mathrm{~s} / \mathrm{d} 8$

- Lobby Tunggu \& Lobby lift menggunakan jenis lampu Surface Mounted Flourescent 21 Watt sebanyak 32 unit Mounted Flourescent 28 Watt sebanyak 10 unit, Reccesed Mounted Downlight 18 Watt sebanyak 4 unit, ruangan lainnya menggunakan Surface Mounted Flourescent 72 Watt

Tabel 12. Beban ruangan lantai 4

\begin{tabular}{|c|c|c|c|c|c|c|c|c|c|}
\hline \multirow{2}{*}{ Ruangan } & \multicolumn{9}{|c|}{ Jenis beban ruangan } \\
\hline & $\begin{array}{c}\mathrm{O} \\
\text { ra } \\
\mathrm{n} \\
\mathrm{g}\end{array}$ & $\begin{array}{c}\text { Lamp } \\
\text { u }\end{array}$ & $\begin{array}{l}\text { Ko } \\
\text { mp }\end{array}$ & $\begin{array}{c}\text { Pri } \\
\text { nter }\end{array}$ & $\begin{array}{l}\mathrm{T} \\
\mathrm{V}\end{array}$ & $\begin{array}{l}\mathrm{F} \\
\mathrm{a} \\
\mathrm{x}\end{array}$ & $\begin{array}{l}\text { Pro } \\
\text { yek } \\
\text { tor }\end{array}$ & $\begin{array}{c}\text { Dispe } \\
\text { nser }\end{array}$ & $\begin{array}{c}\text { Kulka } \\
\mathrm{s}\end{array}$ \\
\hline Arsip & 1 & 4 & - & - & - & - & - & - & - \\
\hline Kabsudit. Kebijakan & 1 & 4 & 1 & 1 & - & 1 & - & - & - \\
\hline Kabsudit.Program & 1 & 4 & 1 & 1 & - & 1 & - & - & - \\
\hline Bina Program 1 & $\begin{array}{l}8 \\
0\end{array}$ & 100 & 80 & 5 & - & 5 & - & - & - \\
\hline Santai 1 & 4 & 9 & - & - & - & - & - & - & - \\
\hline Kerja Direktur & 1 & 18 & 1 & 1 & 1 & 1 & - & 1 & - \\
\hline Istrahat Direktur & 1 & 1 & - & - & - & - & - & - & - \\
\hline Tunggu, Resepsion & 8 & 16 & - & - & - & - & - & - & - \\
\hline Staff TU & 3 & 6 & 3 & 1 & - & 1 & - & - & - \\
\hline Musholla & 3 & 5 & - & - & - & - & - & - & - \\
\hline Lobby & 5 & 46 & - & - & - & - & - & - & - \\
\hline Kabsudit . Data & 1 & 4 & 1 & 1 & - & - & - & - & - \\
\hline Kabsudit. Perencana & 1 & 4 & 1 & 1 & - & - & - & - & - \\
\hline Kabsudit. Evaluasi & 1 & 4 & 1 & 1 & - & - & - & - & - \\
\hline Bina Pogram 2 & $\begin{array}{l}4 \\
5\end{array}$ & 56 & 45 & 5 & - & 2 & - & - & - \\
\hline Bina Program 3 & $\begin{array}{l}4 \\
5\end{array}$ & 56 & 45 & 5 & - & 2 & - & - & - \\
\hline Santai 2 & 4 & 9 & - & - & - & - & - & - & - \\
\hline
\end{tabular}

Tabel 13. Beban ruangan lantai 5

\begin{tabular}{|c|c|c|c|c|c|c|c|c|c|}
\hline \multirow{2}{*}{ Ruangan } & \multicolumn{9}{|c|}{ Jenis beban ruangan } \\
\cline { 2 - 11 } & Orang & $\begin{array}{c}\text { La } \\
\mathrm{m} \\
\mathrm{pu}\end{array}$ & $\begin{array}{c}\text { Ko } \\
\mathrm{mp}\end{array}$ & $\begin{array}{c}\text { Pri } \\
\text { nter }\end{array}$ & $\begin{array}{c}\mathrm{T} \\
\mathrm{V}\end{array}$ & Fax & $\begin{array}{c}\text { Pro } \\
\text { yek } \\
\text { tor }\end{array}$ & $\begin{array}{c}\text { Dispe } \\
\text { nser }\end{array}$ & $\begin{array}{c}\text { Kulka } \\
\mathrm{s}\end{array}$ \\
\hline Arsip & 1 & 4 & - & - & - & - & - & - & - \\
\hline $\begin{array}{c}\text { Kabsudit. } \\
\text { Kebijakan }\end{array}$ & 1 & 4 & 1 & 1 & - & 1 & - & - & - \\
\hline Kabsudit.Program & 1 & 4 & 1 & 1 & - & 1 & - & - & - \\
\hline $\begin{array}{c}\text { Bagian pengelolaan } \\
\text { SDA 1 }\end{array}$ & 80 & 10 & 80 & 5 & - & 5 & - & - & - \\
\hline Santai 1 & 4 & 9 & - & - & - & - & - & - & - \\
\hline Kerja Dit & 1 & 18 & 1 & 1 & 1 & 1 & - & 1 & - \\
\hline Istrahat Dit & 1 & 1 & - & - & - & - & - & - & - \\
\hline $\begin{array}{c}\text { Tunggu } \\
\text { Resepsion }\end{array}$ & 8 & 16 & - & - & - & - & - & - & - \\
\hline Staff TU & 3 & 6 & 3 & 1 & - & 1 & - & - & - \\
\hline Musholla & 3 & 5 & - & - & - & - & - & - & - \\
\hline Lobby & 5 & 46 & - & - & - & - & - & - & - \\
\hline $\begin{array}{c}\text { Kabsudit . } \\
\text { Perencana1 }\end{array}$ & 1 & 4 & 1 & 1 & - & - & - & - & - \\
\hline $\begin{array}{c}\text { Kabsudit. } \\
\text { Perencana 2 }\end{array}$ & 1 & 4 & 1 & 1 & - & - & - & - & - \\
\hline Kabsudit. Evaluasi & 1 & 4 & 1 & 1 & - & - & - & - & - \\
\hline $\begin{array}{c}\text { Bagian pengelolaan } \\
\text { SDA2 2 }\end{array}$ & 45 & 56 & 45 & 5 & - & 2 & - & - & - \\
\hline $\begin{array}{c}\text { Bagian } \\
\text { Pengelolaan SDA 3 }\end{array}$ & 45 & 56 & 45 & 5 & - & 2 & - & - & - \\
\hline Santai 2 & 4 & 9 & - & - & - & - & - & - & \\
\hline
\end{tabular}

Tabel 14. Beban ruangan lantai 6

\begin{tabular}{|c|c|c|c|c|c|c|c|c|c|}
\hline \multirow[b]{2}{*}{ Ruangan } & \multicolumn{9}{|c|}{ Jenis beban ruangan } \\
\hline & Orang & Lampu & $\begin{array}{c}\mathrm{K} \\
\mathrm{o} \\
\mathrm{m} \\
\mathrm{p}\end{array}$ & $\begin{array}{c}\text { Prin } \\
\text { ter }\end{array}$ & $\begin{array}{l}\mathrm{T} \\
\mathrm{V}\end{array}$ & $\begin{array}{c}\mathrm{Fa} \\
\mathrm{x}\end{array}$ & $\begin{array}{c}\mathrm{Pr} \\
\text { oy } \\
\text { ek } \\
\text { to } \\
\mathrm{r}\end{array}$ & $\begin{array}{c}\text { Dispe } \\
\text { nser }\end{array}$ & $\begin{array}{c}\text { Kulk } \\
\text { as }\end{array}$ \\
\hline Arsip & 1 & 4 & - & - & - & - & - & - & - \\
\hline Kabsudit. Pel 1 & 1 & 4 & 1 & 1 & - & 1 & - & - & - \\
\hline Kabsudit.Pel 2 & 1 & 4 & 1 & 1 & - & 1 & - & - & - \\
\hline Pantai \& rawa 1 & 80 & 100 & 80 & 5 & - & 5 & - & - & - \\
\hline Santai & 4 & 9 & - & - & - & - & - & - & - \\
\hline Kerja Dit & 1 & 18 & 1 & 1 & 1 & 1 & - & 1 & - \\
\hline Istrahat Dit & 1 & 1 & - & - & - & - & - & - & - \\
\hline Tunggu, Resepsion & 8 & 16 & - & - & - & - & - & - & - \\
\hline Staff TU & 3 & 6 & 3 & 1 & - & 1 & - & - & - \\
\hline Musholla & 3 & 5 & - & - & - & - & - & - & - \\
\hline Lobby & 5 & 46 & - & - & - & - & - & - & - \\
\hline Kabsudit .Perencana & 1 & 4 & 1 & 1 & - & - & - & - & - \\
\hline $\begin{array}{c}\text { Kabsudit. } \\
\text { Pengamanan }\end{array}$ & 1 & 4 & 1 & 1 & - & - & - & - & - \\
\hline $\begin{array}{c}\text { Kabsudit. } \\
\text { Pendayagunaan }\end{array}$ & 1 & 4 & 1 & 1 & - & - & - & - & - \\
\hline Pantai \& rawa 2 & 45 & 56 & 45 & 5 & - & 2 & - & - & - \\
\hline Pantai \& rawa 3 & 45 & 56 & 45 & 5 & - & 2 & - & - & - \\
\hline Santai & 4 & 9 & - & & - & - & - & - & \\
\hline
\end{tabular}

Tabel 15. Beban ruangan lantai 7

\begin{tabular}{|c|c|c|c|c|c|c|c|c|c|}
\hline \multirow[b]{2}{*}{ Ruangan } & \multicolumn{9}{|c|}{ Jenis beban ruangan } \\
\hline & $\begin{array}{c}\text { Ora } \\
\text { ng }\end{array}$ & $\begin{array}{c}\text { Lamp } \\
\text { u }\end{array}$ & $\begin{array}{l}\text { Ko } \\
\text { mp }\end{array}$ & $\begin{array}{l}\text { Pri } \\
\text { nter }\end{array}$ & $\begin{array}{l}\mathrm{T} \\
\mathrm{V}\end{array}$ & $\begin{array}{l}\mathrm{F} \\
\mathrm{a}\end{array}$ & $\begin{array}{c}\text { Proye } \\
\text { ktor }\end{array}$ & $\begin{array}{c}\text { Dispe } \\
\text { nser }\end{array}$ & $\begin{array}{c}\text { Kulka } \\
\text { s }\end{array}$ \\
\hline Arsip & 1 & 4 & - & - & - & - & - & - & - \\
\hline Kabsudit. Pel 1 & 1 & 4 & 1 & 1 & - & 1 & - & - & - \\
\hline Kabsudit.Pel 2 & 1 & 4 & 1 & 1 & - & 1 & - & - & - \\
\hline $\begin{array}{c}\text { Sungai } \& \text { waduk } \\
1\end{array}$ & 80 & 100 & 80 & 5 & - & 5 & - & - & - \\
\hline Santai & 4 & 9 & - & - & - & - & - & - & - \\
\hline Kerja Dir & 2 & 18 & 1 & 1 & 1 & 1 & - & 1 & - \\
\hline Istrahat Dir & 1 & 1 & - & - & - & - & - & - & - \\
\hline $\begin{array}{l}\text { Koridor, } \\
\text { Resepsion }\end{array}$ & 8 & 16 & - & - & - & - & - & - & - \\
\hline Staff TU & 3 & 6 & 3 & 1 & - & 1 & - & - & - \\
\hline Musholla & 3 & 5 & - & - & - & - & - & - & - \\
\hline Lobby & 5 & 46 & - & - & - & - & - & - & - \\
\hline $\begin{array}{l}\text { Kabsudit : } \\
\text { konservasi }\end{array}$ & 1 & 4 & 1 & 1 & - & - & - & - & - \\
\hline $\begin{array}{c}\text { Kabsudit. } \\
\text { Perencana1 }\end{array}$ & 1 & 4 & 1 & 1 & - & - & - & - & - \\
\hline $\begin{array}{c}\text { Kabsudit. } \\
\text { Penanggulangan }\end{array}$ & 1 & 4 & 1 & 1 & - & - & - & - & - \\
\hline $\begin{array}{c}\text { Sungai } \& \text { waduk } \\
2\end{array}$ & 45 & 56 & 45 & 5 & - & 2 & - & - & - \\
\hline $\begin{array}{c}\text { Sungai \& Waduk } \\
3 \\
\end{array}$ & 45 & 56 & 45 & 5 & - & 2 & - & - & - \\
\hline Santai & 4 & 9 & - & - & - & - & - & - & - \\
\hline
\end{tabular}

Tabel 16. Beban ruangan lantai 8

\begin{tabular}{|c|c|c|c|c|c|c|c|c|c|}
\hline \multirow[b]{2}{*}{ Ruangan } & \multicolumn{9}{|c|}{ Jenis beban ruangan } \\
\hline & $\begin{array}{c}\text { Ora } \\
\text { ng }\end{array}$ & $\begin{array}{c}\text { Lamp } \\
\text { u }\end{array}$ & $\begin{array}{l}\text { Ko } \\
\text { mp }\end{array}$ & $\begin{array}{l}\text { Pri } \\
\text { nter }\end{array}$ & $\begin{array}{l}\mathrm{T} \\
\mathrm{V}\end{array}$ & $\begin{array}{l}\mathrm{F} \\
\mathrm{a}\end{array}$ & $\begin{array}{l}\text { Proye } \\
\text { ktor }\end{array}$ & $\begin{array}{c}\text { Dispe } \\
\text { nser }\end{array}$ & $\begin{array}{c}\text { Kulka } \\
\text { s }\end{array}$ \\
\hline Arsip & 1 & 4 & - & - & - & - & - & - & - \\
\hline Kabsudit. Pel 1 & 1 & 4 & 1 & 1 & - & 1 & - & - & - \\
\hline Kabsudit.Pel 2 & 1 & 4 & 1 & 1 & - & 1 & - & - & - \\
\hline Irigasi 1 & 80 & 100 & 80 & 5 & - & 5 & - & - & - \\
\hline Santai & 4 & 9 & - & - & - & - & - & - & - \\
\hline Kerja Dir & 2 & 18 & 1 & 1 & 1 & 1 & - & 1 & - \\
\hline Istrahat Dir & 1 & 1 & - & - & - & - & - & - & - \\
\hline $\begin{array}{l}\text { Koridor, } \\
\text { Resepsion }\end{array}$ & 8 & 16 & - & - & - & - & - & - & - \\
\hline Staff TU & 3 & 6 & 3 & 1 & - & 1 & - & - & - \\
\hline Musholla & 3 & 5 & - & - & - & - & - & - & - \\
\hline Lobby & 5 & 46 & - & - & - & - & - & - & - \\
\hline $\begin{array}{l}\text { Kabsudit } \\
\text {.evaluasi }\end{array}$ & 1 & 4 & 1 & 1 & - & - & - & - & - \\
\hline $\begin{array}{c}\text { Kabsudit. } \\
\text { Perencana1 }\end{array}$ & 1 & 4 & 1 & 1 & - & - & - & - & - \\
\hline $\begin{array}{c}\text { Kabsudit. } \\
\text { Perencana } 2\end{array}$ & 1 & 4 & 1 & 1 & - & - & - & - & - \\
\hline Irigasi 1 & 45 & 56 & 45 & 5 & - & 2 & - & - & - \\
\hline Irigasi 2 & 45 & 56 & 45 & 5 & - & 2 & - & - & - \\
\hline Santai & 4 & 9 & - & - & - & - & - & - & - \\
\hline
\end{tabular}


5. Material bangunan

a. Dinding eksterior

Dinding eksterior keseluruhan terdiri dari kaca reflective Glass Blue Dark ketebalan $8 \mathrm{~mm}$, dengan koofisien perpindahan panas $0,861 \mathrm{Btu} / \mathrm{hr} . \mathrm{ft}^{2}{ }^{\circ} \mathrm{F}$

b. Dinding partisi

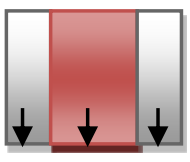

$$
\begin{array}{lll}
1 & 2 & 3
\end{array}
$$

Gambar 2. Konstruksi dinding partisi $\mathrm{U}_{\text {total }}$ dinding partisi $=0,529 \mathrm{Btu} / \mathrm{hr} \mathrm{ft}^{2}{ }^{0} \mathrm{~F}$ c. Lantai

Top surface Still air

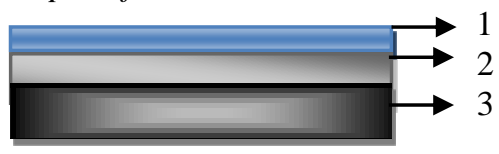

Bottom surface Still air

Gambar 3. Konstruksi lantai

$\mathrm{U}_{\text {total }}$ untuk konstruksi lantai $=0.33 \mathrm{Btu} / \mathrm{hr}$ $\mathrm{ft}^{20} \mathrm{~F}$

\section{Perhitungan Beban Pendingin}

Hasil perhitungan beban pendinginan lantai 1 s/d 8 disajikan dalam tabel 17 :

Tabel 17. Total Beban Pendingin lantai 1 s/d 8

\begin{tabular}{|c|c|c|c|c|c|c|}
\hline No. & LANTAI & $\begin{array}{c}\text { Qs } \\
\text { (Btu/hr) }\end{array}$ & $\begin{array}{c}\text { QI } \\
\text { (Btu/hr) }\end{array}$ & $\begin{array}{c}\text { RSH } \\
\text { (Btu/hr) }\end{array}$ & $\begin{array}{c}\text { RLH } \\
\text { (Btu/hr) }\end{array}$ & $\begin{array}{c}\text { RTH } \\
\text { (Btu/hr) }\end{array}$ \\
\hline 1 & Satu & 927021 & 204819 & 1019723 & 225301 & 1245024 \\
\hline 2 & Dua & 822879 & 172938 & 905167 & 190232 & 1095400 \\
\hline 3 & Tiga & 1122474 & 284537 & 1234722 & 312991 & 1547712 \\
\hline 4 & Empat & 1122474 & 284537 & 1234722 & 312991 & 1547712 \\
\hline 5 & Lima & 1122474 & 284537 & 1234722 & 312991 & 1547712 \\
\hline 6 & Enam & 1122474 & 284537 & 1234722 & 312991 & 1547712 \\
\hline 7 & Tujuh & 1122474 & 284537 & 1234722 & 312991 & 1547712 \\
\hline 8 & Delapan & 1122474 & 284537 & 1234722 & 312991 & 1547712 \\
\hline 9 & Total & 8484744 & 2084979 & 9333222 & 2293479 & 11626701 \\
\hline
\end{tabular}

\section{Distribusi Udara}

Kebutuhan suplai udara ruangan dapat dihitung dengan persamaan :

$$
\mathrm{SCFM}_{\mathrm{s}}=\frac{\mathrm{RSH}}{1,10 \mathrm{x} \text { (trm-ts })}
$$

Didapat kebutuhan suplai udara perlantai:
Tabel 18. Suplai udara lantai 1

\begin{tabular}{|c|c|c|c|c|c|c|}
\hline N0 & RUANGAN & $\begin{array}{c}\text { RSH } \\
(\mathbf{B t u} / \mathbf{h r})\end{array}$ & $\begin{array}{c}\text { RTH } \\
(\mathbf{B t u} / \mathbf{h r})\end{array}$ & $\begin{array}{c}\text { RSHR } \\
(\mathbf{t s}\end{array}$ & $\begin{array}{c}\mathbf{S C F M}_{\mathbf{s}} \\
(\mathbf{C F M})\end{array}$ \\
\hline 1 & Food Court & 295936 & 356176 & 0,83 & 50 & 11497 \\
\hline 2 & Tenant & 174646 & 216652 & 0,81 & 49 & 6506,92 \\
\hline 3 & Lobby & 227060 & 246719 & 0,92 & 53 & 10118,53 \\
\hline 4 & Gallery & 215249 & 291584 & 0,74 & 43 & 6436,82 \\
\hline 5 & Mitra 1 & 25038 & 32671 & 0,77 & 46 & 830,72 \\
\hline 6 & Mitra 2 & 25038 & 32671 & 0,77 & 46 & 830,72 \\
\hline 7 & Mitra 3 & 25038 & 32671 & 0,77 & 46 & 830,72 \\
\hline 8 & Koridor & 14217 & 16853 & 0,84 & 50,5 & 669,03 \\
\hline 9 & R. UPS & 17501 & 19028 & 0,92 & 53 & 779,90 \\
\hline & Tottal & & & & 38500,4 \\
\hline
\end{tabular}

\begin{tabular}{|c|c|c|c|c|c|c|}
\hline No. & Ruangan & $\begin{array}{c}\text { RSH } \\
(\text { Btu/hr) }\end{array}$ & $\begin{array}{c}\text { RTH } \\
\text { (Btu/hr) }\end{array}$ & RSHR & $\begin{array}{c}\text { ts } \\
\left({ }^{\circ} \mathrm{F}\right)\end{array}$ & $\begin{array}{l}\text { SCFM }_{\mathrm{s}} \\
(\mathrm{CFM})\end{array}$ \\
\hline 1 & Lobby & 119038 & 126070 & 0,94 & 54 & 5578,16 \\
\hline 2 & Bagian Umum & 287318 & 378919 & 0,76 & 45,5 & 9361,94 \\
\hline 3 & Kabag Umum & 28899 & 30426 & 0,95 & 54,5 & 1390 \\
\hline 4 & Arsip & 15759 & 17286 & 0,91 & 52,5 & 685,47 \\
\hline 5 & Rapat 1 & 47221 & 70121 & 0,67 & 29 & 966,85 \\
\hline 6 & Seketraris Direktur & 71701 & 73227 & 0,98 & 56,5 & 3856,96 \\
\hline 7 & Istirahat Sek. Direk & 9437 & 10964 & 0,86 & 51,5 & 391,73 \\
\hline 8 & $\begin{array}{c}\text { TU. Resepsion } 1 \& \\
\text { Longe } 1\end{array}$ & 46660 & 58873 & 0,79 & 47 & 1606,74 \\
\hline 9 & Musholla & 19183 & 23762 & 0,81 & 49 & 714,71 \\
\hline 10 & $\begin{array}{c}\text { TU. Resepsion } 2 \& \\
\text { Longe } 2\end{array}$ & 53054 & 65267 & 0,81 & 49 & 1976,67 \\
\hline 11 & Lounge 3 & 27165 & 34798 & 0,78 & 46,5 & 918,04 \\
\hline 12 & Kerja direktur & 114320 & 115846 & 0,99 & 57 & 6337 \\
\hline 13 & Istirahat direktur & 15078 & 16605 & 0,91 & 52,5 & 655,85 \\
\hline \multirow[t]{2}{*}{14} & Rapat 2 & 50335 & 73235 & 0,69 & 30 & 1054,35 \\
\hline & Total & & & & & 35494,47 \\
\hline
\end{tabular}

Tabel 19. Suplai udara lantai 2

Tabel 20. Suplai udara lantai 3

\begin{tabular}{|c|c|c|c|c|c|c|}
\hline No. & RUANGAN & $\begin{array}{c}\text { RSH } \\
(\mathbf{B t u} / \mathbf{h r})\end{array}$ & $\begin{array}{c}\mathbf{R T H} \\
(\mathbf{B t u} / \mathbf{h r})\end{array}$ & $\mathbf{S H R}$ & $\begin{array}{c}\text { ts } \\
\left({ }^{\circ} \mathbf{F}\right)\end{array}$ & $\begin{array}{c}\mathbf{S C F M}_{\mathbf{s}} \\
(\mathbf{C F M})\end{array}$ \\
\hline 1 & Ruang Arsip & 15759 & 17286 & 0,91 & 52,5 & 685,47 \\
\hline 2 & Kabsudit. Evaluasi1 & 20538 & 22064 & 0,93 & 53,5 & 938,23 \\
\hline 3 & $\begin{array}{c}\text { Kabag } \\
\text { Kepegawaian }\end{array}$ & 20538 & 22064 & 0,93 & 53,5 & 938,23 \\
\hline 4 & $\begin{array}{c}\text { Bagian } \\
\text { Kepegawaian }\end{array}$ & 389036 & 511192 & 0,76 & 45,5 & 12676,31 \\
\hline 5 & Santai 1 & 36363 & 42470 & 0,86 & 51,5 & 1509,49 \\
\hline 6 & Kerja direktur & 88894 & 90421 & 0,98 & 56,5 & 4781,81 \\
\hline 7 & Istirahat Direk & 9170 & 10696 & 0,86 & 51,5 & 380,65 \\
\hline 8 & Tunggu, Resepsion & 44047 & 56261 & 0,78 & 46,5 & 1488,57 \\
\hline 9 & Staff TU & 26016 & 30597 & 0,85 & 51,5 & 1078 \\
\hline 10 & Musholla & 19183 & 23762 & 0,81 & 49 & 714,71 \\
\hline 11 & Lobby & 55763 & 63396 & 0,88 & 52 & 2368,86 \\
\hline 12 & Kabag hukum & 10224 & 11750 & 0,87 & 51,5 & 424,4 \\
\hline 13 & Kabag Keuangan & 11257 & 12784 & 0,88 & 52 & 478,2 \\
\hline 14 & Kabsudit Evaluasi & 10224 & 11750 & 0,87 & 51,5 & 424,4 \\
\hline 15 & Bagian Keuangan & 212098 & 280798 & 0,76 & 45,5 & 6911,98 \\
\hline 16 & Bagian Hukum & 219513 & 288213 & 0,76 & 45,5 & 7152,59 \\
\hline 17 & Santai 2 & 46101 & 52207 & 0,88 & 52 & 1958,41 \\
\hline & Total & & & & & 44910,31 \\
\hline
\end{tabular}

Untuk perhitungan suplai udara ruang pada lantai 4 s/d 8, hasilnya sama dengan lantai 3. 
ANALISA HASIL PERHITUNGAN

\section{Perbandingan Beban Pendinginan}

Dari hasil perhitungan ulang beban pendinginan yang dilakukan pada gedung perkantoran.X di Jakarta, dapat dianalisa kenaikan beban pendinginan eksisting lantai $1 \mathrm{~s} / \mathrm{d} 8$, dengan beban yang didapat dari hasil perancangan ulang.

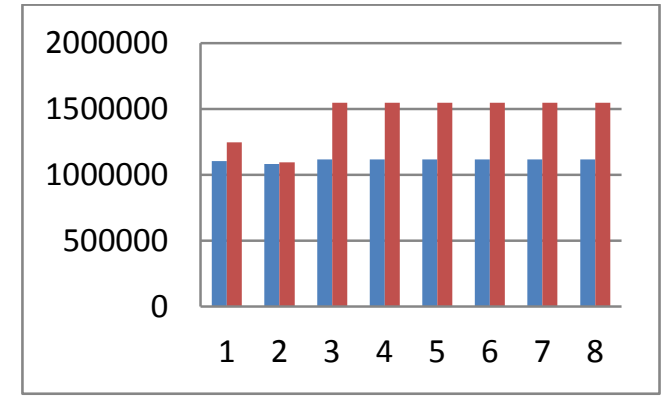

Gambar 4. Grafik Perbandingan Beban Pendinginan Eksisting dan Perhitungan Ulang

Total beban eksisting lantai 1 s/d 8 sebesar 8.880.000 Btu/hr. Pada lantai satu menggunakan 3 unit AHU masing - masing menerima beban sebesar $312.000 \mathrm{Btu} / \mathrm{hr}$, 420.000 Btu/hr , 372.000 Btu/hr . Dan pada lantai dua menggunakan 2AHU masingmasing menerima beban sebesar 540.000 $\mathrm{Btu} / \mathrm{hr}$, dan untuk lantai tiga sampai dengan 8 masing- masing menggunakan 2 AHU, masing - masing AHU menerima beban sebesar $612.000 \mathrm{Btu} / \mathrm{hr}$, dan 504.000 Btu/hr

Setelah dilakukannya perhitungan ulang beban pendinginan pada gedung perkantoran .X dengan menggunakan datadata baru didapat beban pendinginan sebesar 11.626.701 Btu/ hr. Beban pendinginan mengalami kenaikan seperti yang terlihat pada gambar 4. Hal tersebut terjadi dikarenakan bertambahnya jumlah penghuni dalam gedung, peralatan elektronik, penerangan, rata- rata temperatur udara luar gedung yang semakin panas. Maka dapat diketahui kenaikan beban pendinginan lantai 1 s/d 8 sebesar 2.746.701 Btu/hr, dengan prosentase kenaikan sebesar 30,9\%

\section{Perbandingan Suplai Udara}

Pada lantai satu terdapat 3 AHU masing - masing menerima beban suplai udara sebesar 9.282 CFM, 12.495 CFM, 11.067 CFM. Pada lantai dua menggunakan 2 AHU masing- masing menerima beban suplai udara sebesar 16.065 CFM, serta pada lantai tiga sampai dengan 8 masing- masing menggunakan 2 AHU ,masing - masing AHU menerima beban suplai udara sebesar 18.207 CFM, 14.994 CFM.

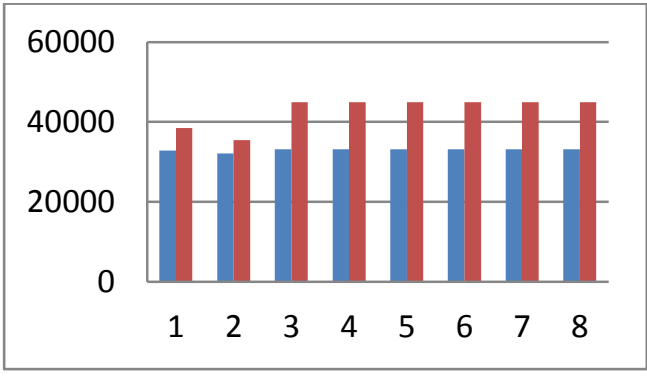

Gambar 5. Grafik Perbandingan Suplai Udara Eksisting dan Perhitungan Ulang

Pada gambar 5 terlihat total kapasitas suplai udara eksiting sebesar 264.180 CFM dan total kapasitas suplai udara hasil perancangan ulang sebesar 343.456,73CFM. Maka dapat diketahui kenaikan kebutuhan suplai udara lantai 1 s/d 8 sebesar79.275,73 CFM atau sebesar $30 \%$. Kenaikan tersebut terjadi karena besar beban pendinginan pada setiap lantai mengalami kenaikan sehingga sangat berpengaruh terhadap kapasitas jumlah suplai udara yang dibutuhkan.

\section{Analisa Chiller Unit}

Sistem pendingin udara pada gedung saat ini menggunakan Air Cooled Chiller. dengan beban Chiller eksisting sebesar 750 Ton Refrigeran, dengan menggunakan 4 Chiller unit masing-masing sebesar 250 Ton Refrigeran, dan 1 Chiller unit stand by sebagai back up. Seperti yang terlihat pada gambar 6 


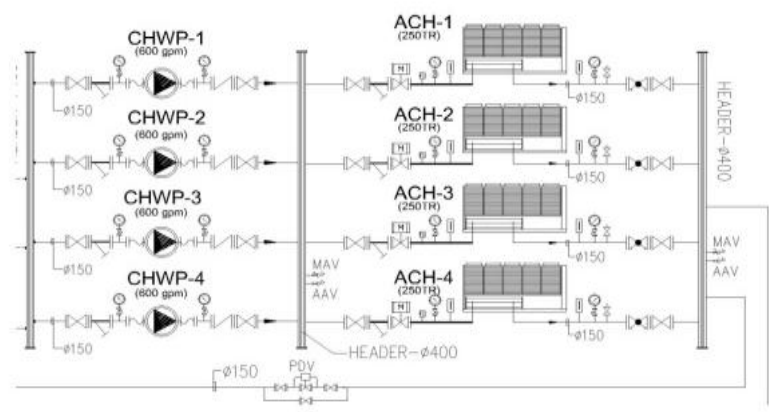

Gambar 6. Skematik Sistem Chiller

Dari data - data perhitungan ulang diperoleh beban panas eksternal dan internal gedung lantai $1 \mathrm{~s} / \mathrm{d} 8$ sebagai

Room Total Heat (RTH) sebesar = 11.626.701 Btu/hr

1 Ton Refrigerant $=12.000 \mathrm{Btu} / \mathrm{hr}$

Kapasitas Chiller unit $=\frac{\text { Total Beban }}{12.000 \mathrm{Btu} / \mathrm{hr}}$

$$
=\frac{11.626 .701 \mathrm{Btu} / \mathrm{hr}}{12.000 \mathrm{Btu} / \mathrm{hr}}
$$

$=969$ Ton Refrigerant

Sistem pendingin udara tetap menggunakan sistem Air Cooled Chiller tanpa mengubah instalasi. Jadi gedung menggunakan 4 mesin chiller berkapasitas 250 Ton Refrigeran, untuk mengoptimalkan pendinginan maka 4 Chiller unit yang ada harus dioperasikan. Dari data Chiller unit yang ada maka diperoleh spesifikasi sebagai berikut:

Model $=$ RTAC250

Kapasitas $=250$ Ton Refrigerant

Ambient Operating Range $=25^{\circ} \mathrm{F}-115^{\circ} \mathrm{F}$

Leaving Chilled liquid setpoint $=40^{\circ} \mathrm{F}-60$ ${ }^{\circ} \mathrm{F}$

Power Requirements $=380 \mathrm{~V} / 3$ phase $/ 60 \mathrm{~Hz}$

\section{Analisa Air Handling Unit}

Untuk instalasi Air Handling unit pada gedung .X,spesifikasi AHU eksisting kurang memenuhi kapasitas suplai udara yang dibutuhkan untuk setiap lantai atau ruangan. Untuk itu perlu adanya penggantian AHU yang dapat memenuhi kapasitas suplai udara yang dibutuhkan setiap lantai atau ruangan, yang sesuai dengan kapasitas suplai udara hasil perancangan ulang.
Adapun pemilihan AHU sebagai berikut :

AHU.1.A $=11.497 \mathrm{CFM}$

AHU.1.B $=16250,45 \mathrm{CFM}$

AHU.1.C $=10.377,91 \mathrm{CFM}$

AHU.2.A $=18.259,69 \mathrm{CFM}$

AHU.2.B $=17.234,78 \mathrm{CFM}$

AHU.3.A $=24.476,76 \mathrm{CFM}$

AHU.3.B $=20.433,55 \mathrm{CFM}$

Untuk AHU.4.A sampai dengan AHU.8.A menerima beban sama dengan AHU.3.A. dan untuk AHU.4.B sampai dengan AHU.8.B menerima beban sama dengan AHU.3.B.

\section{KESIMPULAN}

Dari hasil perancangan ulang sistem HVAC, maka dapat disimpulkan beberapa hal sebagai berikut :

1. Beban pendinginan eksisting sebesar 8.880.000 Btu/hr. Dari hasil perhitungan ulang beban pendinginan lantai $1 \mathrm{~s} / \mathrm{d} 8$ diperoleh sebesar 11.626.701 Btu/hr. Terjadi kenaikan sebesar 30,9\%.

2. Suplai udara eksisting sebesar 264.180 CFM. Dari hasil perhitungan ulang lantai 1 s/d 8 diperoleh kebutuhan suplai udara sebesar 343.456,73 CFM. Terjadi kenaikan sebesar $30 \%$.

3. Dari hasil perhitungan diperoleh kapasitas Chiller sebesar 969 Ton Refrigeran, sehingga menggunakan 4 unit Chiller dengan masing -masing kapasitas 250 Ton Refrigeran (tanpa stand by unit) dan, tanpa mengubah instalasi terpasang.

4. Pada lantai 1 menggunakan 3 Air Handling Unit (AHU). lantai 2 menggunakan 2 AHU, serta lantai 3 s/d 8 masing- masing menggunakan 2 AHU. Dengan total 17 Unit AHU yang direncanakan pada lantai $1 \mathrm{~s} / \mathrm{d} 8$.

5. Dari hasil rancangan ducting dengan menggunakan diagram friction loss, dan software duct calculator, dengan nilai friction loss $=(0,1$ in. $\mathrm{wg} / 100 \mathrm{ft})$. 
diperoleh dimensi ducting terbesar 35 in (22 in $\mathrm{x} 48$ in ) dan dimensi ducting terkecil 9,5 in ( 8 in $x 9$ in).

\section{DAFTAR PUSTAKA}

ASHRAE HANDBOOK 2009, American

Society of Heating Refrigerating and Air Conditioning Engineers Inc, Atlanta. Inch-Pound Edition

Arismunandar, Wiranto \& Heizo Saito, 2005, Penyegaran Udara, Cetakan Ke-7, Pradnya Paramita, Jakarta.

Carrier Air Conditioning Company, Handbook of Air Conditioning System Design, McGraw Hill Company, New York.

Rudoy, William. 1980, Cooling and Heating Load Calculation Manual. Washington D.C : Departement of Housing and Urban Development.

Stoecker, Wilbert F \& Jerold W. Jones, 1994, Refrigerasi dan Pengkondisian Udara, Edisi Ke-2, Erlangga. Jakarta. 